\title{
The impact of prior outpatient ACE inhibitor use on 30-day mortality for patients hospitalized with community-acquired pneumonia
}

\author{
Eric M Mortensen*1,2, Marcos I Restrepo ${ }^{1,3}$, Antonio Anzueto ${ }^{3}$ and \\ Jacqueline Pugh ${ }^{1,2}$
}

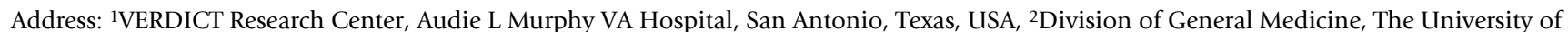
Texas Health Science Center at San Antonio, USA and ${ }^{3}$ Division of Pulmonary and Critical Care Medicine, The University of Texas Health Science Center at San Antonio, USA

Email: Eric M Mortensen* - mortensen@verdict.uthscsa.edu; Marcos I Restrepo - MRestrepo@verdict.uthscsa.edu; Antonio Anzueto - anzueto@uthscsa.edu; Jacqueline Pugh - jpugh@verdict.uthscsa.edu

* Corresponding author

Published: 13 September 2005

BMC Pulmonary Medicine 2005, 5:12 doi:10.1 186/I47|-2466-5-12
Received: 06 April 2005

Accepted: 13 September 2005

This article is available from: http://www.biomedcentral.com/I47I-2466/5/12

(C) 2005 Mortensen et al; licensee BioMed Central Ltd.

This is an Open Access article distributed under the terms of the Creative Commons Attribution License (http://creativecommons.org/licenses/by/2.0), which permits unrestricted use, distribution, and reproduction in any medium, provided the original work is properly cited.

\begin{abstract}
Background: Recent studies suggest that angiotensin-converting enzyme (ACE) inhibitors may have beneficial effects for patients at risk for some types of infections. We examined the effect of prior outpatient use of ACE inhibitors on mortality for patients hospitalized with communityacquired pneumonia.
\end{abstract}

Methods: A retrospective cohort study conducted at two tertiary teaching hospitals. Eligible subjects were admitted with a diagnosis of, had a chest x-ray consistent with, and had a discharge ICD-9 diagnosis of pneumonia. Subjects were excluded if they were "comfort measures only" or transferred from another acute care hospital. Subjects were considered to be on a medication if they were taking it at the time of presentation.

Results: Data was abstracted on 787 subjects at the two hospitals. Mortality was $9.2 \%$ at 30 -days and $13.6 \%$ at 90 -days. At presentation $52 \%$ of subjects were low risk, $34 \%$ were moderate risk, and $14 \%$ were high risk. In the multivariable conditional logistic regression analysis, after adjusting for potential confounders, the use of ACE inhibitors at presentation (odds ratio $0.44,95 \%$ confidence interval $0.22-0.89$ ) was significantly associated with 30-day mortality.

Conclusion: Prior outpatient use of an ACE inhibitor was associated with decreased mortality in patients hospitalized with community-acquired pneumonia despite their use being associated with comorbid illnesses likely to contribute to increased mortality. Confirmatory studies are needed, as well as research to determine the mechanism(s) of this protective effect.

\section{Background}

Community-acquired pneumonia is the seventh leading cause of death and the leading cause of infectious death in the United States [1]. Although mortality due to commu- nity-acquired pneumonia decreased significantly with the introduction of antibiotics in the 1950s since that time mortality has been stable or increasing [2]. Despite this, only a few new classes of antibiotics have been added to 
the armamentarium for treating community-acquired pneumonia in the last 20 years and no new classes of medications beyond antibiotics have been added since the 1950 s.

Recent studies have demonstrated that elderly patients taking ACE inhibitors have significantly decreased rates of aspiration pneumonia and may have decreased mortality [3-5]. The hypothesized reason for this protective effect is an increase in substance $P$ which accentuates the cough reflex. Other studies have demonstrated significant changes in systemic cytokine levels for subjects treated with ACE inhibitors [6-8]. These cytokines play an important role in host defense mechanisms for patients with community-acquired pneumonia but under certain conditions may lead to septic shock or acute respiratory distress syndrome (ARDS) [9-11].

The study aim was to assess the effects of prior outpatient ACE inhibitor use on 30-day mortality for patients hospitalized with community-acquired pneumonia.

\section{Methods}

This a retrospective cohort study of patients hospitalized with community-acquired pneumonia at 2 academic tertiary care hospitals in San Antonio, Texas. Both hospitals are teaching affiliates of the University of Texas Health Science Center at San Antonio. The Institutional Review Board of the University of Texas Health Science Center at San Antonio approved the research protocol with exempt status.

\section{Study sites/inclusion and exclusion criteria}

We identified all patients admitted to the study hospitals between January 1, 1999 and December 1, 2002 with a primary discharge diagnosis of pneumonia (ICD-9 codes 480.0-483.99 or 485-487.0) or secondary discharge diagnosis of pneumonia with a primary diagnosis of respiratory failure (518.81) or sepsis (038.xx). Subjects were included if they were 1 ) greater than 18 years of age, 2) had an admission diagnosis of community-acquired pneumonia documented in the medical record, and 3) had a radiographically confirmed infiltrate or other finding consistent with community-acquired pneumonia on chest x-ray or CT obtained within 24 hours of admission.

Exclusion criteria included 1) having been discharged from an acute care facility within 14 days of admission, 2) transfer after being admitted to another acute care hospital, and 3) being comfort measures only on this admission. If a subject was admitted more than once during the study period, only the first hospitalization was abstracted

\section{Data abstraction}

Chart review data included: demographics, comorbid conditions, physical examination findings, laboratory data, and chest radiograph reports. In addition, data on important processes of care measures for patients hospitalized with community-acquired pneumonia were also abstracted: first dose of antibiotics within 8 hours of admission, collection of blood cultures prior to antibiotic administration, and obtaining blood cultures and oxygen saturation measurement within 24 hours of presentation [12]. Antimicrobial therapy was considered guidelineconcordant if it agreed with either the 2000 Infectious Diseases Society of America or 2001 American Thoracic Society guidelines $[13,14]$. Information on all outpatient medications that were either 1 ) reported as currently being taken by the patient at presentation, or 2) listed in the electronic medical record, were recorded.

Mortality was assessed using information from the Texas Department of Health and Department of Veteran Affairs clinical database. Mortality status was assessed through December 31, 2002.

\section{Risk adjustment}

The pneumonia severity index was used to assess severity of illness at presentation [15]. The pneumonia severity index is a validated prediction rule for 30-day mortality in patients with community-acquired pneumonia. This rule is based on three demographic characteristics, five comorbid illnesses, five physical examination findings, and seven laboratory and radiographic findings from the time of presentation. Patients are classified into five risk classes with 30 -day mortality ranging from $0.1 \%$ for class I to $27 \%$ for class V for patients enrolled in the PORT cohort study [15].

\section{Outcome}

We used 30-day mortality as the outcome for this study. Previous research has demonstrated that 30-day mortality is primarily due to the community-acquired pneumonia rather than other co-existing co-morbid conditions $[16,17]$. Therefore by using 30-day mortality as our outcome we are able to minimize the effect of the ACE inhibitor use on other co-morbid conditions.

\section{Statistical analyses}

Univariate statistics were used to test the association of sociodemographic and clinical characteristics with allcause 30-day mortality. Categorical variables were analyzed using the Chi-square test and continuous variables were analyzed using Student's t-test.

A propensity score technique was used to balance covariates associated with ACE inhibitor use between groups $[18,19]$. The use of the propensity score technique 
Table I: Subject Demographic and Clinical Characteristics by 30-Day Mortality*

\begin{tabular}{|c|c|c|c|}
\hline \multirow[b]{2}{*}{ Variable } & \multicolumn{2}{|c|}{ 30-Day Mortality } & \multirow[b]{2}{*}{ p-value } \\
\hline & Alive $(n=714)$ & Dead $(n=72)$ & \\
\hline Age, years +/- standard deviation & $60.2+/-16.4$ & $62.9+/-16.4$ & 0.09 \\
\hline Men & $56 \mid(79)$ & $60(83)$ & 0.3 \\
\hline Nursing home resident & $4 I(6)$ & $13(18)$ & $<0.001$ \\
\hline Emergency department admission & $598(84)$ & $58(81)$ & 0.5 \\
\hline Admitted to intensive care $\leq 24$ hours & $118(17)$ & $36(50)$ & $<0.001$ \\
\hline \multicolumn{4}{|l|}{ Preexisting Comorbid Conditions } \\
\hline Congestive heart failure & $105(15)$ & $18(25)$ & 0.02 \\
\hline Chronic pulmonary disease & $195(27)$ & $23(3 \mathrm{I})$ & 0.4 \\
\hline History of stroke & $93(13)$ & $12(17)$ & 0.4 \\
\hline Chronic liver disease & $83(12)$ & $11(15)$ & 0.4 \\
\hline History of malignancy & $58(8)$ & $20(28)$ & $<0.001$ \\
\hline Renal insufficiency & $74(10)$ & $13(18)$ & 0.05 \\
\hline \multicolumn{4}{|c|}{ History, Physical, Laboratory, and Radiographic Data } \\
\hline Altered mental status & $68(10)$ & $17(24)$ & $<0.001$ \\
\hline Respiratory rate $>30$ per minute & $71(10)$ & $11(15)$ & 0.2 \\
\hline Systolic blood pressure $<90 \mathrm{mmHg}$ & $16(2)$ & $5(7)$ & 0.02 \\
\hline Heart rate $>125$ per minute & $86(12)$ & $19(26)$ & 0.001 \\
\hline Temperature $<95^{\circ}$ or $>104^{\circ}$ & $19(3)$ & $2(3)$ & 0.9 \\
\hline Arterial $\mathrm{pH}<7.35$ & $37(5)$ & $12(17)$ & $<0.001$ \\
\hline Arterial oxygenation $<90 \%$ & $149(21)$ & $27(38)$ & 0.001 \\
\hline Hematocrit $<30 \%$ & $64(9)$ & $8(11)$ & 0.5 \\
\hline Blood urea nitrogen $>30 \mathrm{mg} / \mathrm{dL}$ & $135(19)$ & $33(46)$ & $<0.001$ \\
\hline Serum glucose $>250 \mathrm{mg} / \mathrm{dL}$ & $71(10)$ & $5(7)$ & 0.4 \\
\hline Serum sodium $<130 \mathrm{meq} / \mathrm{L}$ & $98(14)$ & $18(25)$ & 0.01 \\
\hline Pleural effusion & $160(11)$ & $29(35)$ & 0.001 \\
\hline \multicolumn{4}{|l|}{ Pneumonia Severity Index } \\
\hline Class I-III & $393(54)$ & $16(22)$ & \\
\hline Class IV & $240(34)$ & $26(36)$ & \\
\hline Class V & $82(12)$ & $30(42)$ & $<0.001$ \\
\hline \multicolumn{4}{|l|}{ Processes of Care } \\
\hline Initial antibiotics within 4 hours & $201(28)$ & $22(3 \mathrm{l})$ & 0.7 \\
\hline Initial antibiotics within 8 hours & $358(50)$ & $36(50)$ & 1.0 \\
\hline Blood cultures prior to antibiotics & $540(76)$ & $55(76)$ & 0.9 \\
\hline Oxygenation assessed $\leq 24$ hours & $538(75)$ & $65(90)$ & 0.004 \\
\hline Guideline-concordant antibiotics & $574(80)$ & $5 I(7 I)$ & 0.05 \\
\hline \multicolumn{4}{|l|}{ Outpatient Medications } \\
\hline ACE inhibitor & $183(25)$ & $11(15)$ & 0.05 \\
\hline
\end{tabular}

* Data are presented as number $(\%)$ or mean $+/$-standard deviation

provides a way, in non-randomized studies, to control for pretreatment differences by defining sets of comparable patients. The propensity score was derived from a logistic regression model, and a dichotomous indicator variable indexing whether a patient was on an ACE inhibitor was our dependent variable. The covariates used to develop the propensity score included the pneumonia severity index (which includes comorbid conditions such as congestive heart failure and chronic renal insufficiency), history of hypertension, and history of diabetes mellitus.

A multivariable conditional logistic regression model was derived with 30-day mortality as the dependent variable, and the propensity score as the matching variable [20]. The independent variables in the model were the use of
ACE inhibitor at presentation, and process of care measures (initial antibiotics within 8 hours and obtaining blood cultures prior to initial dose of antibiotics, and whether antimicrobial therapy was guideline concordant). Interactions were assessed using cross-product terms between the medications and all of the other variables retained in the models. No significant interactions terms were noted, so they were excluded from the final models. All analyses were performed using STATA version 8 (Stata Corporation, College Station, Texas).

\section{Results}

Data was abstracted on 787 patients at the two hospitals. The mean age was 60 years with a standard deviation of 16 years. The population was $79 \%$ male, $84 \%$ were admitted 
Table 2: Use versus non-use of ACE inhibitors by demographic and clinical characteristics*

\begin{tabular}{|c|c|c|c|}
\hline \multirow[b]{2}{*}{ Variable } & \multicolumn{2}{|c|}{ ACE Inhibitor Use } & \multirow[b]{2}{*}{ p-value } \\
\hline & $\begin{array}{l}\text { Not on ACE inhibitor } \\
(n=593)\end{array}$ & $\begin{array}{l}\text { On ACE inhibitor } \\
(n=194)\end{array}$ & \\
\hline Age, years +/- standard deviation & $58.2+/-16.9$ & $67.1+/-13.6$ & $<0.001$ \\
\hline Men & 467 (79) & $154(80)$ & 0.8 \\
\hline Nursing home resident & $43(7)$ & $I I(6)$ & 0.4 \\
\hline Emergency department admission & $498(84)$ & $\mid 58(8 \mid)$ & 0.38 \\
\hline Admitted to intensive care $\leq 24$ hours & $116(20)$ & $38(20)$ & 1.0 \\
\hline \multicolumn{4}{|l|}{ Preexisting Comorbid Conditions } \\
\hline Diabetes Mellitus & $138(23)$ & $92(47)$ & $<0.001$ \\
\hline Coronary artery disease & $132(22)$ & $98(51)$ & $<0.001$ \\
\hline Chronic pulmonary disease & $15 \mid(25)$ & $67(35)$ & $<0.001$ \\
\hline Current tobacco use & $200(31)$ & $35(18)$ & $<0.001$ \\
\hline Congestive heart failure & $59(10)$ & $64(33)$ & $<0.001$ \\
\hline History of stroke & $67(11)$ & $38(20)$ & 0.003 \\
\hline Chronic liver disease & $82(14)$ & $12(6)$ & 0.004 \\
\hline History of malignancy & $57(10)$ & $21(I I)$ & 0.6 \\
\hline Renal insufficiency & $54(9)$ & $33(17)$ & 0.002 \\
\hline \multicolumn{4}{|c|}{ History, Physical, Laboratory, and Radiographic Data } \\
\hline Altered mental status & $62(10)$ & $23(12)$ & 0.6 \\
\hline Respiratory rate $>30$ per minute & $67(11)$ & $15(8)$ & 0.16 \\
\hline Systolic blood pressure $<90 \mathrm{mmHg}$ & $17(3)$ & $4(2)$ & 0.5 \\
\hline Heart rate $>125$ per minute & $87(15)$ & 18(9) & 0.06 \\
\hline Temperature $<95^{\circ}$ or $>104^{\circ}$ & $18(3)$ & $3(2)$ & 0.26 \\
\hline Arterial $\mathrm{pH}<7.35$ & $33(6)$ & 16(8) & 0.18 \\
\hline Arterial oxygenation $<90 \%$ & $128(22)$ & $48(25)$ & 0.4 \\
\hline Hematocrit $<30 \%$ & $59(10)$ & $13(7)$ & 0.17 \\
\hline Blood urea nitrogen $>30 \mathrm{mg} / \mathrm{dL}$ & $110(19)$ & $58(30)$ & $<0.001$ \\
\hline Serum glucose $>250 \mathrm{mg} / \mathrm{dL}$ & $50(8)$ & $26(13)$ & 0.04 \\
\hline Serum sodium < $130 \mathrm{meq} / \mathrm{L}$ & $95(16)$ & $2 I(I I)$ & 0.08 \\
\hline Pleural effusion & $|4|(24)$ & $48(25)$ & 0.8 \\
\hline \multicolumn{4}{|l|}{ Pneumonia Severity Index } \\
\hline Class I-III & $332(56)$ & $77(40)$ & \\
\hline Class IV & $187(32)$ & $79(41)$ & \\
\hline Class V & $74(12)$ & $38(20)$ & $<0.001$ \\
\hline
\end{tabular}

* Data are presented as number (\%) or mean +/-standard deviation

through the emergency department, and 20\% were admitted to the intensive care unit within the first 24 hours after admission. Mortality was $9.2 \%$ at 30 -days and $13.6 \%$ at 90-days. By pneumonia severity index, 52\% were low risk (pneumonia severity index classes I-III), 34\% were moderate risk (pneumonia severity index class IV), and $14 \%$ were high risk (pneumonia severity index class V). Regarding community-acquired pneumonia-related processes of care, $28 \%$ received the initial dose of antibiotics within 4 hours of presentation and an additional $22 \%$ received the initial antibiotic dose within 8 hours, $76 \%$ of patients had blood cultures obtained within 24 hours and prior to antibiotics, and oxygenation was assessed at presentation in $91 \%$.

Table 1 shows the demographic factors, clinical characteristics, and processes of care data for this population by 30day mortality. In the univariate analysis numerous indi- vidual components of the pneumonia severity index were significantly associated with 30-day mortality including age, nursing home residency, history of congestive heart failure, history of malignancy, altered mental status, systolic blood pressure $<90 \mathrm{mmHg}$, tachycardia $>125$ beats per minute, arterial acidosis, elevated blood urea nitrogen 30 $\mathrm{mg} / \mathrm{dl}$, serum sodium $<130 \mathrm{meq} / \mathrm{l}$, and pleural effusion on chest radiograph. The only processes of care that were statistically significant were the assessment of oxygenation within 24 hours or presentation and use of guidelineconcordant antibiotics. ACE inhibitor use was significantly associated $(\mathrm{p}=0.05)$ with 30-day mortality.

Table 2 demonstrates clinical and demographic variables and the association with use/non-use of ACE inhibitors at presentation. Co-morbid conditions and demographic variables significantly associated with ACE inhibitor use included coronary artery disease, higher age, diabetes mel- 
litus, chronic obstructive pulmonary disease, not currently smoking, congestive heart failure, prior stroke, no history of liver disease, and chronic renal disease. Physical exam and laboratory findings associated with ACE inhibitor use included decreased numbers of patients with heart rates $>125$, higher rates of elevated blood urea nitrogen $>30 \mathrm{mg} / \mathrm{dL}$, lower rates of serum hematocrit $<30 \%$, and higher rates of serum glucose $>250 \mathrm{mg} / \mathrm{dL}$. Of the 787 subjects 194 (25\%) were on ACE inhibitors. There was greater ACE inhibitor use in those who were in the moderate $(30 \%, \mathrm{n}=74)$ and severe $(34 \%, \mathrm{n}=38)$ risk groups versus those with low severity of illness $(19 \%, n=$ 77), $\mathrm{p}<0.001$.

In the multivariable conditional logistic regression analysis after adjusting for potential confounders the use of ACE inhibitors at presentation (odds ratio (OR) 0.44, 95\% confidence interval (CI) 0.22-0.89) was associated with 30-day mortality. The other variables in the model included initial antibiotics within 4 hours (OR 1.09, 95\% CI 0.64-1.85), obtaining blood cultures prior to antibiotics (OR 1.10, 95\% CI 0.6-1.9), oxygenation assessment within 24 hours (OR 1.31, 95\% CI 0.5-3.4), and use of guideline-concordant antimicrobial therapy (OR 0.6, $0.35-1.05)$.

\section{Discussion}

We found that prior outpatient use of ACE inhibitors was associated with decreased 30-day mortality for subjects hospitalized with community-acquired pneumonia. Our findings provide further support to other studies that demonstrate that ACE inhibitor use is associated with decreased mortality for patients with pneumonia.

There are several potential mechanisms for a beneficial effect on mortality for patients on ACE inhibitors. ACE inhibitors have been shown in clinical studies to increased serum levels of substance $P$, which is hypothesized to lead to a better gag reflex and increased clearance of secretions [3-5]. Our study specifically excluded patients with a discharge diagnosis of aspiration pneumonia; however, this diagnosis can be clinically difficult to distinguish from community-acquired pneumonia. Other studies have demonstrated that ACE inhibitors have significant immunomodulatory effects on circulating cytokines [6-8]. Therefore the beneficial effect may be due to blunting of the cytokine response so that these patients have lower rates of sepsis and/or ARDS.

Although our study was retrospective and subject to the recognized limitations of such studies, we carefully assembled our cohort from complete patient discharge data to avoid ascertainment bias. Additionally, during chart abstraction we encountered a very small amount $(<5 \%)$ of missing data. Our sample was predominantly men due to the inclusion of a VA hospital and it is possible, but unlikely, that women may have differential responsiveness to ACE inhibitors as compared to men. In addition we are unable to examine whether or not there was significant amounts of non-prescription or non-compliance of ACE inhibitor therapy due to economic considerations. Also we are unable to assess factors such as inpatient continuation of the ACE inhibitor or the dose effect due to the design of this study. Further research is needed to examine these factors. Finally, as in any non-experimental study, we are unable to state conclusively that the prior outpatient use of ACE inhibitors is the cause of decreased mortality in this cohort. However, since patients on ACE inhibitors had significantly higher severity of illness scores at presentation we feel that we have good evidence that these medications may have beneficial effects for patients hospitalized with community-acquired pneumonia.

\section{Conclusion}

In conclusion, our study finds that prior outpatient use of ACE inhibitors reduces mortality for patients with community-acquired pneumonia. Our results add further strength to the existent recommendations to use ACE inhibitors in patients with congestive heart failure, diabetes mellitus, and renal disease, since these patients are at higher risk for either contracting pneumonia or dying from pneumonia when they do contract it. Future research, especially randomized clinical trials, are needed to examine whether either ACE inhibitors are protective when used in an inpatient setting for patients lacking traditional indications for the use of these medications.

\section{Competing interests}

The author(s) declare that they have no competing interests.

\section{Authors' contributions}

EMM originated and coordinated the study, obtained funding, contributed to the analysis of the data, and preparation of the paper.

MIR contributed to the design of the study, contributed to the analysis of the data, and preparation of the paper.

AA contributed to the design of the study, contributed to the analysis of the data, and preparation of the paper.

JP contributed to the design of the study, contributed to the analysis of the data, and preparation of the paper.

\section{Acknowledgements}

Dr. Mortensen was supported by Howard Hughes Medical Institute facultystart up grant 00378-00I and a Department of Veteran Affairs Veterans Integrated Service Network 17 new faculty grant. Dr. Pugh was supported by Department of Veteran Affairs grant HFP98-002. This material is the 
result of work supported with resources and the use of facilities at the South Texas Veterans Health Care System.

The views expressed in this article are those of the authors and do not necessarily represent the views of the Department of Veterans Affairs.

\section{References}

I. Hoyert DL, Arias E, Smith BL: Deaths: Final Data for 1999. Natl Vital Statistics Report 200I, 49(8): I-I I3.

2. Gilbert K, Fine MJ: Assessing prognosis and predicting patient outcomes in community-acquired pneumonia. Seminars in Respiratory Infections 1994, 9(3): I40-152.

3. Nakayama K, Sekizawa K, Sasaki H: ACE inhibitor and swallowing reflex. Chest 1998, I I3(5): I425.

4. Okaishi K, Morimoto S, Fukuo K, Niinobu T, Hata S, Onishi T, Ogihara $\mathrm{T}$ : Reduction of risk of pneumonia associated with use of angiotensin I converting enzyme inhibitors in elderly inpatients. Am J Hypertens 1999, I 2(8 Pt I):778-783.

5. Ohkubo T, Chapman N, Neal B, Woodward M, Omae T, Chalmers ]: Effects of an angiotensin-converting enzyme inhibitor-based regimen on pneumonia risk. Am J Respir Crit Care Med 2004, | 69(9): | $04 \mid$ - | 045.

6. Gullestad L, Aukrust P, Ueland T, Espevik T, Yee G, Vagelos R, Froland SS, Fowler M: Effect of high- versus low-dose angiotensin converting enzyme inhibition on cytokine levels in chronic heart failure. Journal of the American College of Cardiology 1999, 34(7):206I-2067.

7. Alkharfy KM, Kellum JA, Matzke GR: Unintended immunomodulation: part II. Effects of pharmacological agents on cytokine activity. Shock 2000, I3(5):346-360.

8. Skerrett SJ, Park DR: Anti-inflammatory treatment of acute and chronic pneumonia. Seminars in Respiratory Infections 200I, I 6(I):76-84.

9. Moussa K, Michie HJ, Cree IA, McCafferty AC, Winter JH, Dhillon DP, Stephens S, Brown RA: Phagocyte function and cytokine production in community acquired pneumonia. Thorax 1994, 49(2): $|07-|||$.

10. Puren AJ, Feldman C, Savage N, Becker PJ, Smith C: Patterns of cytokine expression in community-acquired pneumonia. Chest 1995, I07(5): 1342-1349.

II. Bauer TT, Monton C, Torres A, Cabello H, Fillela X, Maldonado A, Nicolas JM, Zavala E: Comparison of systemic cytokine levels in patients with acute respiratory distress syndrome, severe pneumonia, and controls. Thorax 2000, 55(I):46-52.

12. Meehan TP, Fine MJ, Krumholz HM, Scinto JD, Galusha DH, Mockalis JT, Weber GF, Petrillo MK, Houck PM, Fine JM: Quality of care, process, and outcomes in elderly patients with pneumonia. JAMA 1997, 278(23):2080-2084.

13. Niederman MS, Mandell LA, Anzueto A, Bass JB, Broughton WA, Campbell GD, Dean N, File T, Fine MJ, Gross PA, Martinez F, Marrie TJ, Plouffe JF, Ramirez J, Sarosi GA, Torres A, Wilson R, Yu VL: Guidelines for the management of adults with communityacquired pneumonia. Diagnosis, assessment of severity, antimicrobial therapy, and prevention. Am J Respir Crit Care Med 200I, I63(7): I730-I754.

14. Bartlett JG, Dowell SF, Mandell LA, File Jr TM, Musher DM, Fine MJ: Practice guidelines for the management of communityacquired pneumonia in adults. Infectious Diseases Society of America. Clin Infect Dis 2000, 3 I (2):347-382.

15. Fine MJ, Auble TE, Yealy DM, Hanusa BH, Weissfeld LA, Singer DE, Coley CM, Marrie TJ, Kapoor WN: A prediction rule to identify low-risk patients with community-acquired pneumonia. $N$ Engl J Med 1997, 336(4):243-250.

16. Mortensen EM, Kapoor WN, Chang CC, Fine MJ: Assessment of mortality after long-term follow-up of patients with community-acquired pneumonia. Clin Infect Dis 2003, 37( I 2): |6 | 7-1624.

17. Mortensen EM, Coley CM, Singer DE, Marrie TJ, Obrosky DS, Kapoor WN, Fine MJ: Causes of death for patients with community-acquired pneumonia: results from the Pneumonia Patient Outcomes Research Team cohort study. Arch Intern Med 2002, I 62(9): 1059-1064.

18. Stone RA, Obrosky DS, Singer DE, Kapoor WN, Fine MJ: Propensity score adjustment for pretreatment differences between hospitalized and ambulatory patients with communityacquired pneumonia. Pneumonia Patient Outcomes
Research Team (PORT) Investigators. Med Care 1995, 33(4 Suppl):AS56-66.

19. Mortensen EM, Restrepo M, Anzueto A, Pugh J: Effects of guideline-concordant antimicrobial therapy on mortality among patients with community-acquired pneumonia. Am J Med 2004, I I 7( I 0):726-73I.

20. Klungel OH, Martens EP, Psaty BM, Grobbee DE, Sullivan SD, Stricker $\mathrm{BH}$, Leufkens HG, de Boer A: Methods to assess intended effects of drug treatment in observational studies are reviewed. Clin Epidemiol 2004, 57( I 2): |223-1231.

\section{Pre-publication history}

The pre-publication history for this paper can be accessed here:

http://www.biomedcentral.com/1471-2466/5/12/prepub
Publish with Biomed Central and every scientist can read your work free of charge

"BioMed Central will be the most significant development for disseminating the results of biomedical research in our lifetime. "

Sir Paul Nurse, Cancer Research UK

Your research papers will be:

- available free of charge to the entire biomedical community

- peer reviewed and published immediately upon acceptance

- cited in PubMed and archived on PubMed Central

- yours - you keep the copyright

Submit your manuscript here:

http://www.biomedcentral.com/info/publishing_adv.asp
BioMedcentral 